\title{
3 Research Square \\ Spectral Discrimination of Six Dominant Seaweed Species in the Intertidal Zone of GouQi Island
}

\author{
jianqu chen \\ Shanghai Ocean University \\ xunmeng li \\ Shanghai Ocean University \\ Kai Wang ( $\sim$ kwang@shou.edu.cn ) \\ Shanghai Ocean University \\ Shouyu Zhang \\ Shanghai Ocean University \\ Jian Zhang \\ Shanghai Ocean University \\ weicheng gao \\ Shanghai Ocean University
}

\section{Research Article}

Keywords: intertidal zone, dominant species, spectral analysis, support vector machine, distinction, fusion model

Posted Date: September 15th, 2021

DOl: https://doi.org/10.21203/rs.3.rs-877541/v1

License: (c) (i) This work is licensed under a Creative Commons Attribution 4.0 International License.

Read Full License 


\section{Abstract}

Probing the coverage and biomass of seaweed is the basis for achieving sustainable utilization of nearshore seaweed resources. Unlike traditional sample surveys, remote sensing technology can realize dynamic monitoring on a large scale and for a long time. In this paper, we measured the spectral data of six dominant seaweed species in different dry and wet conditions in the intertidal zone of Gouqi Island: Ulva pertusa, Sargassum thunbergii, Chondrus ocellatus, Chondria crassiaulis Harv., Grateloupia filicina C. Ag., and Hizikia fusifarme. The different seaweed species were identified and analyzed by a combination of ANOVA and support vector machine (SVM). Fourteen common spectral parameters were used as input variables, and the input parameters were filtered by ANOVA. The samples were divided into a training set (266 samples) and a test set (116 samples) at a 3:1 ratio for input into the SVM model. The results showed that when the input parameters were NDVI $\left(R_{\mathrm{g}}, R_{\mathrm{r}}\right), \mathrm{RVI}\left(R_{\mathrm{g}}, R_{\mathrm{r}}\right), V_{\mathrm{re}}, A_{\mathrm{be}}, L_{\mathrm{be}}, L_{\mathrm{g}}, L_{\mathrm{re}}$, and $R_{\mathrm{r}}$ and the model parameters $\mathrm{g}=1.30$ and $\mathrm{c}=2.85$, the maximum discrimination rate of the six different wet and dry states of seaweed was $74.96 \%$, and the highest accuracy was $93.94 \%$ when distinguishing different phyla of seaweed ( $\mathrm{g}=6.85$ and $\mathrm{c}=2.55$ ). In addition, SVM is fused with XGBoost (eXtreme Gradient Boosting) by vote and further classified in combination with the selected parameters. The accuracy of the six seaweeds was $73.98 \%$ (vote mean score $=0.972$ ). In this study, the spectral data of intertidal seaweed in different dry and wet states were classified for the first time to provide technical support for remote sensing monitoring of coastal zones and seaweed resource statistics.

\section{Introduction}

Seaweed, as a dominant species of nearshore ecosystems, plays an important role in the conservation of fishery resources and improvement of the water environment. Seaweeds are widely distributed along $25 \%$ of the world's intertidal rocky coastlines, providing a constant source of primary productivity for coastal ecosystems and serving as the foundation for nearshore habitat protection and 'blue carbon' sinks (Fiblee Dexter et al 2016). China's coastal intertidal zone is rich in seaweed resources, mainly Ulva pertusa, Sargassum thunbergii, Chondrus ocellatus, and Hizikia fusifarme. They mainly belong to Chlorophyta, Phaeophyta and Rhodophyta. In recent years, due to the dual influence of man-made factors such as near-shore sewage discharge, rough seaweed harvesting and natural factors such as global warming and ocean acidification, the amount of seaweed resources in China's coastal zone has been decreasing sharply year by year (Wang L. 2011).

To date, studies on the ecology of intertidal seaweed have mainly focused on the diversity composition and seasonal variation characteristics of seaweed communities in local areas, there are few studies on biomass statistics, and the research methods are mostly based on sample sampling, which has a heavy workload and small investigation area. In recent years, marine remote sensing technology has been widely used in coral monitoring and fishery resource assessment (Huang Y. et al 2019; Liu Y. et al 2016). According to Qin Song et al., one of the new trends in seaweed academics and applications is long-term ecological monitoring of seaweed through satellite and drone aerial photography (Li J. Song Q. et al 2020). Among them, spectral analysis, as one of the basic techniques of marine remote sensing, is a 
prerequisite for remote sensing feature identification (Yuhui F et al 2008). Hyperspectral data provide continuous band reflectance, making it easy to distinguish between different feature characteristics $\mathrm{Wu}$ J. et al 2011). The application of hyperspectral techniques to study seaweeds in coastal countries such as the United States, Japan and Australia started earlier. For example, Myers et al. conducted a comparative analysis of the spectral characteristics of nearshore corals and domain seaweed at Lee Stockton, Bahamas, in the Caribbean and explored the spectral variability between the dominant corals and seaweed, providing a method for remote sensing identification of corals (Myers M R et al 1999). To date, hyperspectral techniques have been widely used in the study of terrestrial plants but rarely used in the study of seaweed (Du Z. et al 2020; Liu C et al 2020; Sun H. et al 2019). Only Zheng (Zhang Z. 2014) measured the spectral data of seawater, Ulva prolifera and Sargassum in the Yellow and East China Sea, derived the spectral characteristics of the three and counted the area covered by Ulva prolifera. In addition, many spectroscopy studies have been conducted on seaweed, but they are not precise to specific seaweed "Species" (Cavanaugh K C et al 2010; Ishiguro E et al 2005; Bell T W et al 2015; THOMAS Ë.M. BELL 2015). On the other hand, since the study subjects are distributed in the intertidal zone, they will vary over time, showing different wet and dry states, which are different from exclusively terrestrial or aquatic plants. To provide theoretical guidance for the assessment of intertidal seaweed resources, this study was conducted by classifying seaweeds in different wet and dry states (at the dryout time of two high tides). No studies have been reported on the spectra of seaweed in different dry and wet states.

The intertidal seaweed resources along the coast of Gouqi Island in Shengsi County, Zhejiang Province, China, are relatively abundant, and the dominant seaweed mainly includes Sargassum thunbergii, Ulva pertusa, Chondrus ocellatus and Hizikia fusifarme (Zeng Y. et al 2013). To investigate the characteristics of the intertidal seaweed community of Gouqi Island, this paper investigates the spectral characteristics of six dominant seaweed species (Sargassum thunbergii, Ulva pertusa, Chondrus ocellatus, Chondria crassiaulis, Hizikia fusifarme, and Grateloupia filicina) of different phyla and different wet and dry states. The spectral reflectance characteristics of different seaweeds were analyzed, and 14 common spectral parameters were screened by variance analysis combined with variable reduction (VACVR). The spectral parameters screened were used to classify seaweeds, and a discrimination model was established to identify different species of seaweeds, which can provide technical support for remote sensing monitoring of intertidal seaweeds. To fit the actual situation, the spectra of six seaweeds in different dry and wet states are considered. Mainly divided into three dries out degrees: measured immediately after collection (wettest), measured after waiting for the two highest tide times after collection (driest), measured at any time within the waiting time for two high tides (moderately dry and wet).

\section{Materials And Methods}

\section{Sample Collection and Preparation}

Located in the southern Ma'an Islands in Shengsi County, Zhejiang Province, China, Gouqi Island has many reefs and rich biological resources in nearby waters, with unique natural geomorphology and 
intertidal biodiversity features. The nearshore substrate is mostly rocky reefs, where many seaweeds grow and thrive, forming a complex nearshore marine ecosystem (Zuli W et al 2019). The seaweeds of Gouqi Island are most abundant in summer and autumn every year, and the survey period of this study is October 17-24, 2019, and January 1-7, 2021, 11:30 - 13:30 (UTC/GMT + 08:00). To reduce the influence of human activities and mussel farming on the growth of intertidal seaweeds and to ensure that the survey sites are representative, Miaogan Village (122.793125E, 30.723037N) and Houtou Bay (122.777962E, 30.727135N) were selected as the seaweed spectral data collection sites (Fig. 1).

Spectral data collection of dominant intertidal seaweed species was performed by an ASD Field Spec Handheld (Field Spec Handheld, ASD, USA). Its wavelength observation range is 325 nm-1075 nm, including the visible and near infrared bands that are widely used for vegetation research, with a spectral sampling interval of $1 \mathrm{~nm}$, a spectral resolution of $3 \mathrm{~nm}$, and a field of view of $25^{\circ}$.

Spectrometer optimization was performed every 10-15 min, and dark currents were collected every 5 min. Before the spectral measurement of the feature, the spectrometer was calibrated against a reference whiteboard to obtain a horizontal straight line with a reflectivity of 1 , and then the spectral measurement of the target feature was performed. After successful completion of spectrometer optimization, dark current acquisition, and whiteboard correction, the spectrometer can be pointed at the target feature, and the spectral data of the target feature can be collected and stored in real time. Three measurement points were randomly selected for the target feature during spectroscopy, and five sets of spectral data were read at $10 \mathrm{~s}$ intervals for each measurement point. A total of 400 target spectral data points were collected in this study. After completing the in situ spectral measurements, some of the experimental seaweeds were collected, brought back to the laboratory to determine their biological parameters and recorded (Chen C. 2019).

\section{Statistical Analysis}

Measured spectral data in the UV band before the wavelength of $400 \mathrm{~nm}$ are noisy, and after $900 \mathrm{~nm}$ is affected by water vapor absorption, they should be eliminated (Chen Q. et al 2015). The mean value of the feature spectral curve is used as the effective spectral value to reduce the effect of noise and randomness.

The spectral reflectance curves of seaweed (a total of six seaweed species) were represented by principal component analysis (PCA) using the first principal component, which was used to analyze the similarities and differences among seaweed spectra. The six seaweeds were grouped, and the pairwise difference $(P)$ between 14 spectral parameters of different seaweeds was obtained by ANOVA (followed by Tukey's post hoc test for multiple comparisons). The spectral parameters were screened by $\mathrm{P}$ and used for classification.

The machine learning method can directly apply the raw spectral data of the features for modeling and prediction and use the overall characteristics of the raw spectra as the discriminative basis for substrate feature classification. The support vector machine (SVM) is a supervised learning method for binary 
classification of data, and its decision boundary is the maximum margin hyperplane solved for the test set, allowing for dimensionality reduction of high-dimensional data (Nguyen Quang $\mathrm{H}$ et al 2021), which has the advantages of small sample size, generality, and robustness (Liu B. et al 2020). Zhang et al. (Zhang J. et al 2020) used different classification methods, such as the spatially adaptive full variance method based on multiple logistic regression and the spatial feature extraction method based on superpixels, to classify spectral remote sensing images and concluded that the SVM algorithm using only spectral information can effectively differentiate spectral data. The method of selecting parameters can effectively reduce the amount of computation. In this paper, we apply the soft-margin algorithm to build a support vector machine model to distinguish seaweed spectral data quickly and accurately.

\section{Result}

The dominant seaweeds in the intertidal zone of Gouqi Island were selected for spectroscopic measurements, among which Ulva pertusa was a representative seaweed species of Chlorophyta (Fig. 2a); Sargassum thunbergii and Hizikia fusifarme were representative seaweed species of Phaeophyta (Fig. 2b, 2e); and Chondrus ocellatus, Chondria crassiaulis and Grateloupia filicina were representative seaweed species of Rhodophyta (Fig. 2c, 2d, 2f). Their original spectral features are

analyzed separately, and based on this, more extensive data are applied for separability analysis and establishment of discriminatory criteria.

a) Ulva pertusa; b) Sargassum thunbergii; c) Chondrus ocellatus; d) Chondria crassiaulis; e) Hizikia fusifarme, f) Grateloupia filicina.

\section{Spectral Characteristics of Six Species}

The spectral curves of the above six species of seaweed were measured by an ASD spectrometer. After preprocessing the spectral data of seaweed in different dry and wet states, the spectral curves of six species of seaweed were drawn (Fig. 3).

a) Chondria crassiaulis; b) Chondrus ocellatus; c) Ulva pertusa; d) Sargassum thunbergii; e) Grateloupia filicina; f) Hizikia fusifarme.

Six species in the visible wavelength band with low reflectance; At the wavelength of $554 \mathrm{~nm}$, Ulva pertusa shows a reflection peak; At wavelengths of $596 \mathrm{~nm}$ and $643 \mathrm{~nm}$, Sargassum thunbergii, Hizikia fusifarme showed reflection peaks; at $648 \mathrm{~nm}$ and $678 \mathrm{~nm}$, Chondrus ocellatus, showed reflection peaks, the reflectance of them is within $30 \%$; In the near-infrared band, the reflectance of six species of seaweed increases suddenly, up to $80 \%$, and the reflectance is higher in the infrared band. According to the literature, the pigments of different phylum species are different (Maxwell K and Johnson G N 2000; Liu Q. 2019) (Table 1). 
Table 1

The similarities and differences of some pigments in different species.

\begin{tabular}{|ll|}
\hline Category & Contained pigment \\
\hline Phaeophyta & Phlorotannins, Carotenoids, chlorophyll a \\
\hline Chlorophyta & Carotenoids, chlorophyll a, chlorophyll b \\
\hline Rhodophyta & Carotenoids, Phycoerythrin, chlorophyll a \\
\hline
\end{tabular}

In this paper, the spectral waveforms of each seaweed are similar to the corresponding phylum reported in many studies. Generally, the distribution of seaweed offshore is as follows: the distribution of green seaweed is the shallowest, followed by brown seaweed, and red seaweed is often in the deepest water layer (Cheng X. 2019). seaweed growing in shallow coastal zones evolved specific mechanisms to resist strong light damage (Melis A 1999). In Phaeophyta, Phlorotannins can resist solar radiation as a kind of light shielding material (Wang Y. et al 2020). In addition, fucoxanthin in Phaeophyta can absorb short wavelength light (Wu Y. et al 2020), so the shading effect of phlorotannins and fucoxanthin may be the main reason for the low reflectivity of Phaeophyta compared with Rhodophyta and Chlorophyta in the wavelength range of 400-900 $\mathrm{nm}$. The spectral curves of the Sargassum thunbergii and Hizikia fusifarme are very similar to that of reported seaweed. There are fine bimodal patterns at $600 \mathrm{~nm}$ and $650 \mathrm{~nm}$, and the maximum reflectivity in the near infrared and infrared bands is $40 \%$ (Zhang Z. 2014; Ishiguro E et al 2005; Stéphane Maritorena et al 1994; Cavanaugh K C et al 2010) (Fig. 3).

In the range of 400-700 nm, the spectral reflectance curve of Ulva pertusa has a peak. The reflectance of the blue-violet band ( $400-492 \mathrm{~nm}$ ) is the lowest, which is $3.6-7.72 \%$. In the yellow green band (492-597 $\mathrm{nm}$ ), due to the reflection of chlorophyll in seaweed, the spectral curve has a broad and prominently high value, approximately $25.27 \%$. In the orange-red band $(597-700 \mathrm{~nm})$, the reflection first decreases and then increases, with a minimum value of 5.78 at $669 \mathrm{~nm}$. In the red edge band $(670-760 \mathrm{~nm})$, the reflectivity increases sharply to $83.4 \%$ (Fig. 3).

Chlorophyll in seaweed can absorb most of the visible light, but when the wavelength is greater than 700 $\mathrm{nm}$, the reflection mechanism of each cell is similar to a small corner reflector, so the cell's structure is also an important factor affecting the reflectivity (Horler D N H et al 1983). Therefore, the electromagnetic reflectance of Ulva pertusa in the red-edge band can rapidly increase from 5-80\%. Due to the lack of active fluorescence absorption on the surface of seaweed (Filella I and Penuelas J 1994), the reflectance of the near infrared shortwave band $(780-900 \mathrm{~nm})$ is approximately $80 \%$.

In the range of 400-700 nm, Sargassum thunbergii and Hizikia fusifarme have three maximum reflectance values. In the blue-violet band $(400-492 \mathrm{~nm})$, the reflectivity is low, approximately $0.85-1.4 \%$. In the yellow-green band (492-597 nm), the reflectivity increases continuously and reaches a maximum at $596 \mathrm{~nm}$, which is approximately $3.74 \%$. In the orange-red band $(597-700 \mathrm{~nm})$, there is another maximum at $643 \mathrm{~nm}$, and the reflectivity is approximately $2.19 \%$. In the red-edge band $(670-760 \mathrm{~nm})$, 
due to the influence of cell structure, the reflectivity increases sharply, and the highest is approximately $34.91 \%$. The reflectivity in the short wave band $(780-900 \mathrm{~nm})$ is approximately $35 \%$.

In the range of $400-700 \mathrm{~nm}$, the total reflectance of Chondrus ocellatus, Chondria crassiaulis and Grateloupia filicina is high in the visible light range, and there are two maxima. In the blue-violet band (400-492 nm), the reflectivity is approximately $30.4-33.79 \%$. In the yellow-green band (492-597 nm), the reflectance first decreases and then increases, and there is a minimum at $536 \mathrm{~nm}$, which is approximately $12.55 \%$. In the orange-red band $(597-780 \mathrm{~nm})$, there are two maxima at $648 \mathrm{~nm}$ and $678 \mathrm{~nm}$, and the reflectivity is approximately $33.87 \%$ and $32.31 \%$, respectively. In the red edge band $(670-760 \mathrm{~nm})$, due to the influence of cell structure, the reflectivity rises sharply, and the highest is approximately $86.04 \%$. In the near-infrared $(780-900 \mathrm{~nm})$ shortwave band, the reflectivity is maintained at approximately $85 \%$.

\section{Analysis and Optimal Screening of Spectral Parameters of Seaweeds}

The spectral parameters of the 14 commonly used compounds were screened by ANOVA. The original data were analyzed by variance, and the significance between different seaweed species ( $P$, Supplementary material) was obtained. The smaller the $P$, the greater the significance. The 14 parameters (Table 2) were used as input variables to derive the initial discriminant accuracy. The corresponding parameters are eliminated according to $\mathrm{P}$ from large to small until the model reaches the optimal discriminative accuracy. 
Table 2

14 commonly used spectral parameters.

\begin{tabular}{|c|c|c|c|}
\hline Parameters types & Parameters & Symbol & Definition \\
\hline \multirow[t]{8}{*}{$\begin{array}{l}\text { Location } \\
\text { parameters }\end{array}$} & $\begin{array}{l}\text { Green peak } \\
\text { amplitude }\end{array}$ & $R_{\mathrm{g}}$ & $\begin{array}{l}\text { Maximum reflectivity of } 510-560 \mathrm{~nm} \text { in green } \\
\text { light range }\end{array}$ \\
\hline & $\begin{array}{l}\text { Green peak } \\
\text { loction }\end{array}$ & $L_{g}$ & $\begin{array}{l}\text { Wavelength of green peak in the green range of } \\
510-560 \mathrm{~nm}\end{array}$ \\
\hline & $\begin{array}{l}\text { Red valley } \\
\text { amplitude }\end{array}$ & $R_{\mathrm{r}}$ & $\begin{array}{l}\text { Maximum reflectivity of } 640-680 \mathrm{~nm} \text { in red light } \\
\text { range }\end{array}$ \\
\hline & $\begin{array}{l}\text { Red valley } \\
\text { location }\end{array}$ & $L_{\mathrm{r}}$ & $\begin{array}{l}\text { Wavelength corresponding to Red Valley } 640- \\
680 \mathrm{~nm} \text { in red light range }\end{array}$ \\
\hline & $\begin{array}{l}\text { Red edge } \\
\text { amplitude }\end{array}$ & $V_{\text {re }}$ & $\begin{array}{l}\text { Maximum value of first order differential in red } \\
\text { edge } 680-760 \mathrm{~nm}\end{array}$ \\
\hline & $\begin{array}{l}\text { Red edge } \\
\text { location }\end{array}$ & $L_{\mathrm{re}}$ & $\begin{array}{l}\text { Wavelength corresponding to red edge } \\
\text { amplitude }\end{array}$ \\
\hline & $\begin{array}{l}\text { Blue edge } \\
\text { amplitude }\end{array}$ & $V_{\text {be }}$ & $\begin{array}{l}\text { First order differential maximum in } 490-530 \mathrm{~nm} \\
\text { of blue edge }\end{array}$ \\
\hline & $\begin{array}{l}\text { Blue edge } \\
\text { location }\end{array}$ & $L_{\text {be }}$ & $\begin{array}{l}\text { Band length corresponding to blue edge } \\
\text { amplitude }\end{array}$ \\
\hline \multirow[t]{2}{*}{ Area parameters } & Red edge area & $A_{\text {re }}$ & $\begin{array}{l}\text { Sum of first order differential values in the range } \\
\text { of red edge }\end{array}$ \\
\hline & Blue edge area & $A_{\mathrm{be}}$ & $\begin{array}{l}\text { Sum of first order differential values in the range } \\
\text { of blue edge }\end{array}$ \\
\hline \multirow[t]{4}{*}{$\begin{array}{l}\text { Vegetation index } \\
\text { Parameters }\end{array}$} & $R_{\mathrm{g}} / R_{\mathrm{r}}$ & $\begin{array}{l}\mathrm{RVI}\left(R_{\mathrm{g}}\right. \\
\left.R_{\mathrm{r}}\right)\end{array}$ & Amplitude ratio of green peak to Red Valley \\
\hline & $A_{\mathrm{re}} / A_{\mathrm{be}}$ & $\begin{array}{l}\mathrm{RVI}\left(A_{\mathrm{re}}\right. \\
\left.A_{\mathrm{be}}\right)\end{array}$ & Area ratio of red edge to blue edge \\
\hline & $\left(R_{\mathrm{g}}-R_{\mathrm{r}}\right) /\left(R_{\mathrm{g}}+R_{\mathrm{r}}\right)$ & $\begin{array}{l}\text { NDVI } \\
\left(R_{\mathrm{g}}, R_{\mathrm{r}}\right)\end{array}$ & $\begin{array}{l}\text { Normalized ratio of green peak to Red Valley } \\
\text { amplitude }\end{array}$ \\
\hline & $\begin{array}{l}\left(A_{\mathrm{re}}-A_{\mathrm{be}}\right) \\
/\left(A_{\mathrm{re}}+A_{\mathrm{be}}\right)\end{array}$ & $\begin{array}{l}\mathrm{NDVI} \\
\left(A_{\mathrm{re}}, A_{\mathrm{be}}\right)\end{array}$ & $\begin{array}{l}\text { Normalized ratio of red edge area to blue edge } \\
\text { area }\end{array}$ \\
\hline
\end{tabular}

To study the changes in 14 spectral parameters of different seaweed, the first principal component of each spectral parameter in different seaweed species was calculated, and the corresponding characteristics of each spectral parameter of different seaweeds were analyzed by using this value. Each seaweed was subjected to principal component analysis, and their loadings were all greater than $90 \%$, 
indicating that the first principal component can effectively express the information in each seaweed dataset.

The positions of the green peak, red valley, blue edge and red edge are marked on the spectral curve, as shown in Fig. 4. To observe the trends of the spectral parameters more clearly, the four regions corresponding to the reflection spectra and the first-order derivative spectra in regions (a), (b) and (c) and (d) in Fig. 5 are enlarged to obtain four spectral enlargements.

a) Enlarged image of the first-order differential spectrum at $490-530 \mathrm{~nm}$ (blue border area); b): Enlarged image of the spectrum at 510-560 nm (green peak area); c): Enlarged image of the spectrum at $640-680$ $\mathrm{nm}$ (red valley area); d): Enlarged image of the first-order differential spectrum at $680-760 \mathrm{~nm}$ (red area).

Figure 4 shows that there were obvious differences in seaweed spectra among different phyla, while there were small differences among the same species. For example, in (b), the green peak amplitude $R_{\mathrm{g}}$ : in Rhodophyta, Chondria crassiaulis, Chondrus ocellatus and Grateloupia filicina. were $-0.8063,-0.8247$ and -0.8158 , respectively; in Phaeophyta, the values of Sargassum thunbergii and Hizikia fusifarme were -0.7590 and -0.7555 , respectively; and U/va pertusa was -0.5706 . The location of green peak location $L_{g}$ : in the Rhodophyta, the values of Chondria crassiaulis, Chondrus ocellatus and Grateloupia filicina. were $535.6500 \mathrm{~nm}, 521.7119 \mathrm{~nm}$ and $526.5200 \mathrm{~nm}$, respectively; among Phaeophyta, Sargassum thunbergii and Hizikia fusifarme were 559.8025 and 560.0000, respectively; and Ulva pertusa was 551.1475. The difference in spectral curves among the same phylum was smaller than that among different phyla.

The ANOVA results (Supplementary material) were averaged to represent the $\mathrm{P}$ of the corresponding parameters (Table 3 ). The 14 parameters were selected according to significance, and the parameters with small significance difference were eliminated one by one until the model reached the optimal

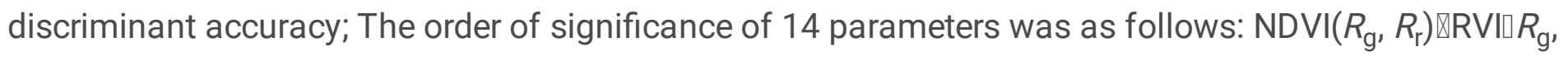

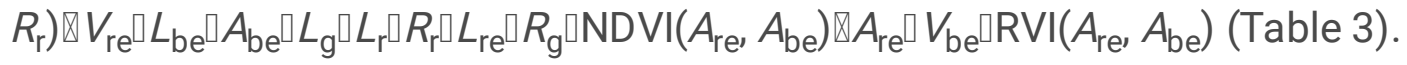


Table 3

$P$ of different spectral parameters.

\begin{tabular}{|ll|}
\hline Spectral parameters & Average P \\
\hline $\operatorname{NDVI}\left(R_{\mathrm{g}}, R_{\mathrm{r}}\right)$ & 0.0300 \\
\hline $\operatorname{RVI}\left(R_{\mathrm{g}}, R_{\mathrm{r}}\right)$ & 0.0340 \\
\hline$V_{\mathrm{re}}$ & 0.0425 \\
\hline$L_{\mathrm{be}}$ & 0.0672 \\
\hline$A_{\mathrm{be}}$ & 0.0739 \\
\hline$L_{\mathrm{g}}$ & 0.0831 \\
\hline$L_{\mathrm{r}}$ & 0.0986 \\
\hline$R_{\mathrm{r}}$ & 0.0986 \\
\hline$L_{\mathrm{re}}$ & 0.1261 \\
\hline$R_{\mathrm{g}}$ & 0.1323 \\
\hline $\mathrm{NDVI}\left(A_{\mathrm{re}}, A_{\mathrm{be}}\right)$ & 0.1581 \\
\hline$A_{\mathrm{re}}$ & 0.1687 \\
\hline$V_{\mathrm{be}}$ & 0.2222 \\
\hline $\mathrm{RVI}\left(A_{\mathrm{re}}, A_{\mathrm{be}}\right)$ & 0.4391 \\
\hline
\end{tabular}

\section{Support Vector Machine (SVM)}

Because the growth environment of intertidal seaweed is different from that of terrestrial and aquatic plants, the rise and fall of tides will affect the spectral reflection curve of seaweed. To eliminate the influence of seawater on the discrimination results and expand the application scenarios, it is necessary to carry out spectral determination of seaweed with different drying degrees. Among them, class 1 represents Chondrus ocellatus, class 2 represents Chondria crassiaulis, class 3 represents Grateloupia filicina, class 4 represents Sargassum thunbergii, class 5 represents Hizikia fusifarme, and class 6 represents Ulva pertusa. A total of 382 groups of data were randomly divided into a training set and a testing set at a ratio of 3:1.

In this paper, the construction of the SVM-based classification model is based on Pytharm in the environment of Python 3.7, mainly using the joblib module of sciket learn SVM (sklearn SVM). The type of kernel function is RBF, and its value equals 2 ; degree $=3$; $\operatorname{coef} 0=0$. 
Table 4

Selection results of spectral characteristic parameters.

\begin{tabular}{|c|c|c|}
\hline Rejected parameters & Parameter quantity & Accuracy $(\%)$ \\
\hline-- & 14 & 40.89 \\
\hline $\operatorname{NDVI}\left(A_{\text {re }}, A_{\text {be }}\right), A_{\text {re, }}, V_{\text {be }}, \operatorname{RVI}\left(A_{\text {re, }}, A_{\text {be }}\right)$ & 10 & 68.34 \\
\hline$R_{\mathrm{g}}, \operatorname{NDVI}\left(A_{\mathrm{re}}, A_{\mathrm{be}}\right), A_{\mathrm{re}}, V_{\mathrm{be}}, \mathrm{RVI}\left(A_{\mathrm{re}}, A_{\mathrm{be}}\right)$ & 9 & 66.02 \\
\hline$L_{\mathrm{re}}, R_{\mathrm{g}}, \operatorname{NDVI}\left(A_{\mathrm{re}}, A_{\mathrm{be}}\right), A_{\mathrm{re}}, V_{\mathrm{be}}, \mathrm{RVI}\left(A_{\mathrm{re}}, A_{\mathrm{be}}\right)$ & 8 & 74.96 \\
\hline$R_{\mathrm{r}}, L_{\mathrm{re}}, R_{\mathrm{g}}, \mathrm{NDVI}\left(A_{\mathrm{re}}, A_{\mathrm{be}}\right), A_{\mathrm{re}}, V_{\mathrm{be}}, \mathrm{RVI}\left(A_{\mathrm{re}}, A_{\mathrm{be}}\right)$ & 7 & 71.96 \\
\hline$L_{r}, R_{\mathrm{r}}, L_{\mathrm{re}}, R_{\mathrm{g}}, \mathrm{NDVI}\left(A_{\mathrm{re}}, A_{\mathrm{be}}\right), A_{\mathrm{re}}, V_{\mathrm{be}}, \mathrm{RVI}\left(A_{\mathrm{re}}, A_{\mathrm{be}}\right)$ & 6 & 64.57 \\
\hline
\end{tabular}

From Table 4, when all 14 parameters were used to distinguish seaweed species, the effect was the worst, only $40.89 \%$. When the parameters with smaller significance (larger $P$ ) were eliminated one by one, the discrimination accuracy increased. Until the four parameters were eliminated, the highest discrimination accuracy was $74.96 \%$. Then, with the decrease in input parameters, the accuracy of discrimination decreased.

When $\operatorname{NDVI}\left(R_{\mathrm{g}}, R_{\mathrm{r}}\right), \mathrm{RVI}\left(R_{\mathrm{g}}, R_{\mathrm{r}}\right), V_{\mathrm{re}}, L_{\mathrm{be}}, A_{\mathrm{be}}, L_{\mathrm{g}}, L_{\mathrm{r}}$, and $R_{\mathrm{r}}$ are selected as input parameters, the optimal parameters of the model are $\mathrm{g}=1.30$ and $\mathrm{c}=2.55$, and the accuracy is $74.96 \%$ (Fig. 6). By outputting the misclassified seaweed species, it was found that there was more misclassification between Rhodophyta and Phaeophyta, especially between different dry and wet conditions; there was no error in seaweed classification among different phyla.

When the same input parameters were selected and the model parameters of different phyla (Chlorophyta: Ulva pertusa; Phaeophyta: Sargassum thunbergii, Hizikia fusifarme, Rhodophyta: Chondrus ocellatus, Chondria crassiaulis, Grateloupia filicina) were optimized, the results showed that when $\mathrm{g}=$ 6.85 and $C=2.55$, the discrimination accuracy was the highest, which was $93.94 \%$ (Fig. 7).

\section{Fusion model}

Because the classification results of only a single model are unsatisfactory, we use the model fusion method to further verify the six kinds of seaweed. SVM and XGBoost are fused by the vote algorithm to obtain the fusion model. By bringing the parameters filtered by SVM into the fusion model, all samples are divided into a training set and test set at a ratio of 7:3, and the classification results and accuracy are calculated. The vote score mean is $97.211 \%$, and the classification results are shown in Fig. 7.

From the classification results, the classification of Category 3 (Ulva pertusa) is correct. There were 12 mismatches among category 1 (Chondria crassiaulis Harv.), category 2 (Chondrus ocellatus) and category 5 (Grateloupia filicina C. Ag.). There were 20 mismatches in Category 4 (Sargassum thunbergii) 
and category 6 (Hizikia fusifarme). The overall accuracy was 73.98\%(Fig. 8), which further confirms the difficulty of spectral data in processing the classification of the same seaweed species.

\section{Discussion}

With increasing Ulva pertusa thickness, the reflectance of Ulva pertusa and Ulva prolifera is similar, and the reflectance of the yellow-green band and near-infrared band increases with increasing seaweed thickness (Zhenglong Z 2014; Yanfang Xiao et al 2019). In this paper, the spectral data of Ulva pertusa with different layers were measured. The results showed that with the increase in the number of layers, the spectral curve of Ulva pertusa was approximately $550 \mathrm{~nm}$ in the near-infrared band, and the reflectance increased exponentially. When it was superposed to three layers, the spectral reflectance of the yellow green band was the highest, approximately $25 \%$, and the near-infrared band was approximately $80 \%$. The spectral reflectance curve of Ulva pertusa increased to 4, 5 and 6 layers and was similar to that of 3 layers, indicating that the spectral reflectance curve of Ulva pertusa reached a saturation state when the number of layers reached 3 , which was very similar to that of Ulva prolifera with different thicknesses. Liu Qing (2019) studied the physiological and biochemical responses of intertidal seaweed to copper stress, and the results showed that the chlorophyll content decreased with increasing Cu2 + in Ulva pertusa (Qin L 2019). Therefore, the chlorophyll content in Ulva pertusa (yellowgreen band) can be used as an indicator of heavy metal pollution in coastal zones.

Although there are few studies on the spectral characteristics of Rhodophyta, it can be found from other studies (such as corals) that Rhodophyta on the surface of bleached coral (Qidong C et al 2015; Filella I and Penuelas J 1994). Through comparative analysis, it is not difficult to find that the spectral characteristics of Rhodophyta are very similar. The minimum value of Rhodophyta in the green band may be due to the absorption of green light by phycoerythrin (Yonghu W 2020).

In summary, the contents of chlorophyll and carotenoids in the same phylum were similar, and the differences among different phyla were obvious. Therefore, it is considered that the same spectrum phenomenon of foreign matter may occur among the same phylum. The higher the plant activity is, the better the chlorophyll activity is, and the higher the spectral reflectance is in the corresponding band (Yanlin T et al 2003), so it is necessary to measure the spectrum of the same seaweed in different seasons to further explore the seasonal variation of the spectral reflectance curve of seaweed. In addition, it has been confirmed that there are gender differences in light adaptation in seaweed (Kuster A. et al 2005). However, the effect of seaweed sex on the spectrum is not considered in this paper, and a followup study needs to be supplemented.

\section{Conclusion}

In this paper, the spectral data of Hizikia fusifarme, Ulva pertusa, Chondria crassiaulis, Sargassum thunbergii and Grateloupia filicina on Gouqi Island were analyzed, and the differences in the spectral characteristics of six seaweed samples were obtained. The main reason was the difference in pigment 
content in seaweed, and the spectral reflectance curves of the same phylum of seaweed were very similar. In addition, the ANOVA results showed that the differences between seaweeds of the same phylum were not significant $(p>0.05)$, while the differences between seaweeds of different phyla were significant $(p \leq$ 0.05).

The support vector machine (SVM) classification model can be used in collaboration with manual identification to identify different seaweed species and improve identification efficiency and accuracy. $\mathrm{NDVI}\left(R_{\mathrm{g}}, R_{\mathrm{r}}\right) \otimes \mathrm{RVI} \square R_{\mathrm{g}}, R_{\mathrm{r}} \square \square V_{\mathrm{re}}^{\square} L_{\mathrm{be}} \square A_{\mathrm{be}} \square L_{\mathrm{g}} \square L_{\mathrm{r}} \square R_{\mathrm{r}}$ were selected as input parameters, and the SVM model constructed with Gaussian kernel function could better distinguish the six seaweed species with an accuracy of $74.96 \%$ when the model parameters $c=1.30$ and $g=2.85$. In misclassification, through the fusion model, the classification accuracy is $73.98 \%$. The difference in seaweed spectrum among the same phylum was small, and the misclassification was large. However, the difference in seaweed spectrum among different phyla was large, and the error rate of misclassification result was low. Using the same method to distinguish the phyla of seaweed (Chlorophyta, Phaeophyta, Rhodophyta), the accuracy reached $93.94 \%$.

In this paper, spectral analysis and classification of dominant seaweed species with different degrees of dryness and wetness on Gouqi Island are carried out, which has good practicability to provide technical support and a partial data basis for remote sensing of intertidal seaweed. The pigment and spectral response mechanisms of different species of the same phylum need to be further studied.

\section{Declarations}

\section{AUTHOR CONTRIBUTIONS}

$\mathrm{KW}$ and SZ conceived and designed the experiments. JC and XL provided the tissue samples. JC performed the experiments and analyzed the data with the help of KW and SZ. JC wrote the manuscript with the advice of $\mathrm{XL}, \mathrm{JZ}$, and WG. All authors provided editorial advice and agreed that this version of the manuscript was acceptable for submission.

\section{FUNDING}

The authors received financial support from the China Agriculture Research System (CARS-50).

\section{ACKNOWLEDGMENTS}

We appreciate the support of our funding agency, the China Agriculture Research System (CARS-50). We also thank the editor and the anonymous reviewers, whose comments significantly improved the manuscript.

\section{References}


Bell T W, Cavanaugh K C, Siegel D A (2015). Remote monitoring of giant kelp biomass and physiological condition: An evaluation of the potential for the Hyperspectral Infrared Imager (HyspIRI) mission. Remote Sens Environ 218-228. doi: 10.1016/j.rse.2015.05.003

Cavanaugh K C, Siegel D A, Kinlan B P, et al (2010). Scaling giant kelp field measurements to regional scales using satellite observations. Marine Ecology Progress 403:13-27. doi: 10.3354/meps08467

Cavanaugh K C, Siegel D A, Kinlan B P, Reed DC (2010). Scaling giant kelp field measurements to regional scales using satellite observations. Mar Ecol-Prog Ser 403(mar.22):13-27. doi: 10.3354/meps08467

Chen C. (2019). Estimation of wheat biomass and yield based on UAV images. Yangzhou University.

Chen Q., Deng R., Qin Y., Xiong L., He Y. (2015). Analysis of spectral characteristics of coral under different growth patterns. Acta Ecologica Sinica 35(10):3394-3402. doi: 10.5846/stxb201306261783

Cheng X. (2019). Response of photosynthetic activity of large seaweed to different environmental conditions. Shanghai Ocean University.

Du Z., Wang L., Bao Y., Zhou X. (2020). Analysis of Hyperspectral Characteristics of Phragmites australis and Spartina alterniflora Leaves in Typical Beach. Chinese Journal of Agrometeorology 41(06):393-402. doi: 10.3969/j.issn.1000-6362.2020.06.006

Fiblee-Dexter, K, Feehan CJ, et al, (2016). Large-scale degradation of a kelp ecosystem in an ocean warming hotspot[J]. Mar Ecol-Prog Ser, 543:141-152. doi: 10.3354/meps11554

Filella I, Penuelas J (1994). The red edge position and shape are indicators of plant chlorophyll content, biomass and hydric status. Int J Remote Sens 15(7):1459-1470. doi: 10.1080/01431169408954177

Horler D N H, Dockray M, Barber J (1983). The red edge of plant leaf reflectance. Int J Remote Sens 4(2):273-288. doi: 10.1080/01431168308948546

Huang Y., Yu K., Wang Y., Liu J., Zhang H. (2019). Progress of the study on coral reef remote sensing. Journal of Remote Sensing 2019, 23(06): 1091-1112. doi: 10.11834/jrs.20198110

Ishiguro E, Yoshimoto S I, Ishikawa D (2005). Monitoring of the Environment around Kagoshima Bay Using Remote Sensing Data -Development of Identifying Method for Seaweeds Growing Region. J Agric Meteoro/ 60(5):409-414. doi: 10.2480/agrmet.409

Kuster A., Schaible R., Schubert (2005). H.S. Sex-specific light acclimation of Chara canescens (Charophyta). Aquat Bot 83,(2):129-140. doi: 10.1016/j.aquabot.2005.05.009

Li J., Song Q., Liu F., Ding L., Liu Z. (2020). New trends in the research and applications of seaweed in response to global change. Chinese Science Bulletion 65(05):334-338. doi: 10.1360/TB-2019-0151 
Liu B., Zuo X., Tan X., Yu A., Guo W. (2020). A deep few-shot learning algorithm for hyperspectral image classification. Acta Geodaetica et Cartographica Sinica 49(10):1331-1342. doi:

10.11947/j.AGCS.2020.20190486.

Liu C., Lin L., Yu C., Wu J. (2020). Research on Peanut Hyperspectral Image Classification Method Based on Deep Learning. Computer Simulation 37(03):189-192+283.

Liu Q. (2019). Physiological and biochemical responses of three intertidal macroalgae to heavy copper stress. Yantai University

Liu Yafei (2016). Marine remote sensing technology and its application research on fisheries. Zhejiang Ocean University

Maxwell K, Johnson G N (2000). Chlorophyll fluorescence a practical guide. J Exp Bot 51(345):659-668. doi: $10.1093 /$ jexbot/51.345.659

Melis A (1999). Photosystem- $\rrbracket$ damage and repair cycle in chloroplasts: what modulates the rate of photodamage?. Trends Plant Sci 4(4):130-135. doi: 10.1016/S1360-1385(99)01387-4

Myers M R, Hardy J T, Mazel C H, et al (1999). Optical spectra and pigmentation of Caribbean reef corals and macroalgae. Coral Reefs 18(2):179-186. doi: 10.1007/s003380050177

Nguyen Quang H. et al. (2021). Stacking segment-based CNN with SVM for recognition of atrial fibrillation from single-lead ECG recordings. Biomed Signal Proces, 68. doi: 10.1016/j.bspc.2021.102672

Stéphane Maritorena, André Morel, Gentili B (1994). Diffuse reflectance of oceanic shallow waters: Influence of water depth and bottom albedo. Limnol Oceanogr39 (7):1689-1703. doi: 10.4319/lo.1994.39.7.1689

Sun H., Liu N., Xing Z., Zhang Z., Li M., Wu J. (2019). Parameter optimization of potato spectral response characteristics and growth stage identification. Spectroscopy and Spectral Analysis 39(06):1870-1877. doi: CNKI:SUN:GUAN.0.2019-06-040

Tang Y., Wu J., Huang J., Wang R., He Q. (2003). Variation law of hypersprctral data and chlorophyll II and carotenoids for rice in the mature process. Chinese Society of Agricultural Engineering (06):167-173. doi: CNKI:SUN:NYGU.0.2003-06-039

THOMAS Ė.M. BELL (2015). Quantifying intertidal macroalgae abundance using aerial photography on the Isle of Wight. Imperial College London.

Wang Lei (2011). Relationship between ecosystem of kelp beds and seasonal variation of fish assemblages in waters around Gouqi Island. ShangHai Ocean University. 
Wang Y., Li J., Chuan Z., Zhong Z., Pang Y., Liu Z. (2020). Photosynthetic characteristics of floating seaweeds and their research progress. Transactions of Oceanology and Limnology (05):105-112. doi: 10.13984/j.cnki.cn37-1141.2020.05.014

Wu J., Peng D (2011). Advances in research on hyperspectral remote sensing forestry information extraction technology. Spectroscopy and Spectral Analysis 31(09):2305-2312. doi:10.3964/j.issn.1000-0593(2011)09-2305-08

Wu Y., Su J. (2020). Study on plant pigments by photoacoustic spectroscopy. Spectroscopy and Spectral Analysis (03):378-380. doi: 10.3321/j.issn:1000-0593.2002.03.008

Wu Z., Zhang S. (2019). Effect of Typhoon on the Distribution of Macroalgae in the Seaweed Beds of Gouqi Island, Zhejiang Province. Journal of Agricultural Science and Technology 21(09):159-168. doi: 10.13304/j.nykjdb.2018.0695

Yan F., Xiao, Jie Z., Ting W., Cui, et al (2019). Remote sensing estimation of the biomass of floating Ulva prolifera and analysis of the main factors driving the interannual variability of the biomass in the Yellow Sea. Mar Pollut Bull 140. doi: 10.1016/j.marpolbul.2019.01.037

Yuhui F, Qijun L, Baoru Z (2008). Spectroscopic analysis of oil spills at sea and satellite information distilling. Journal of Remote Sensing (06):1010-1016. doi: 10.3321/j.issn:1007-4619.2008.06.026

Zeng Y., Ma J., Chen B., Cai Y., Gao S. (2013). Survey on the community of benthic macroalgae on Gouqi Island of Zhejiang Province. Acta Agriculturae ZheJiangensis 25(05):1096-1102. doi: 10.3969/j.issn.1004-1524.2013.05.33

Zhang J., Chen Y. (2020). Overview of hyperspectral image classification methods. Journal of Nanjing University Natural Science 12(01):89-100. doi: 10.13878/j.cnki.jnuist.2020.01.011

Zhang Z. (2014). Remote sensing identification of Ulva prolifra and Sargassum and Evolution of green tide in the Yellow Sea and the East China Sea. East China Normal University.

\section{Figures}




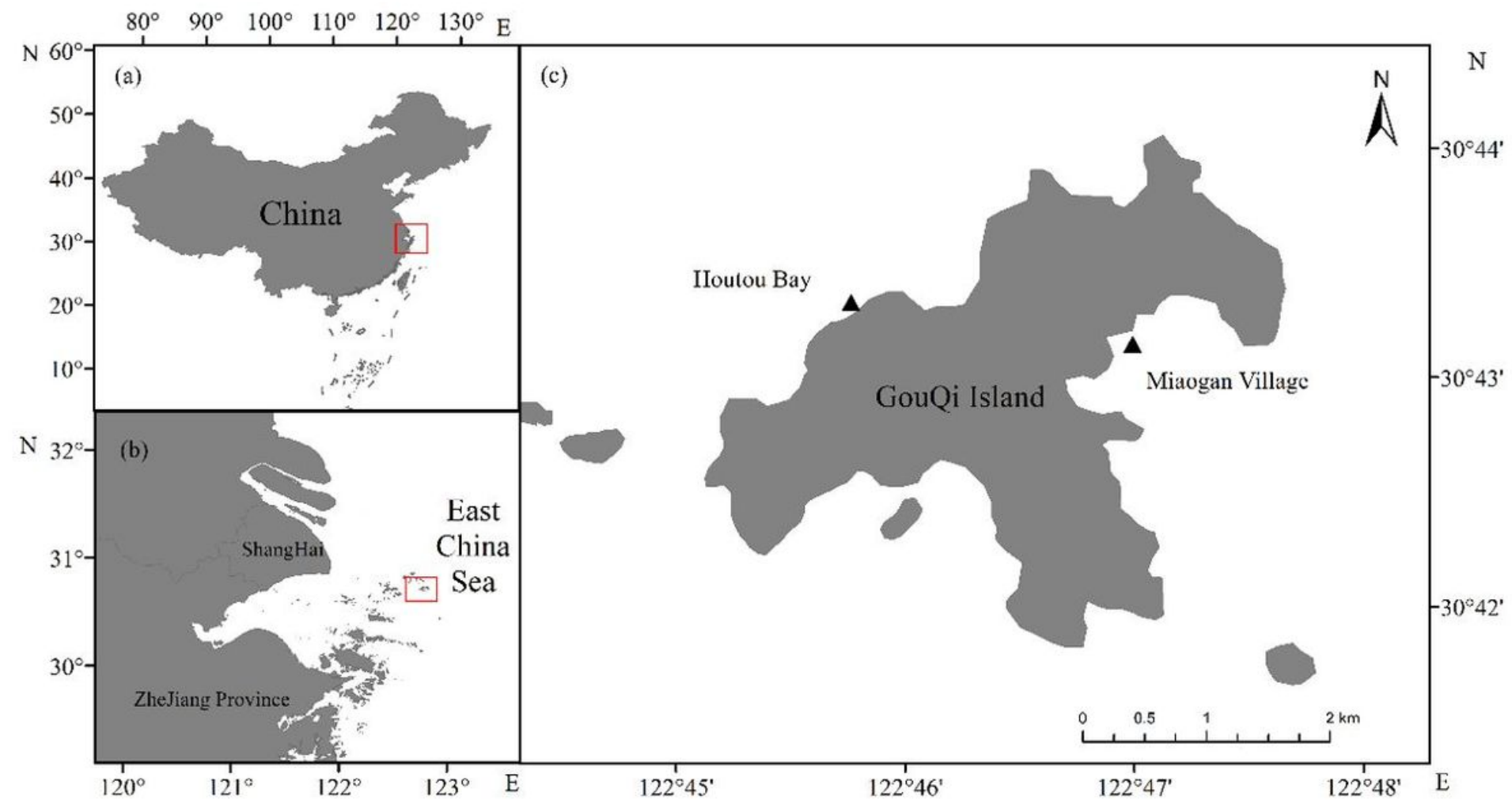

Figure 1

Location map of research. a) China; b) Yangtze River Estuary; c) Survey sites. Triangles indicate samplings.
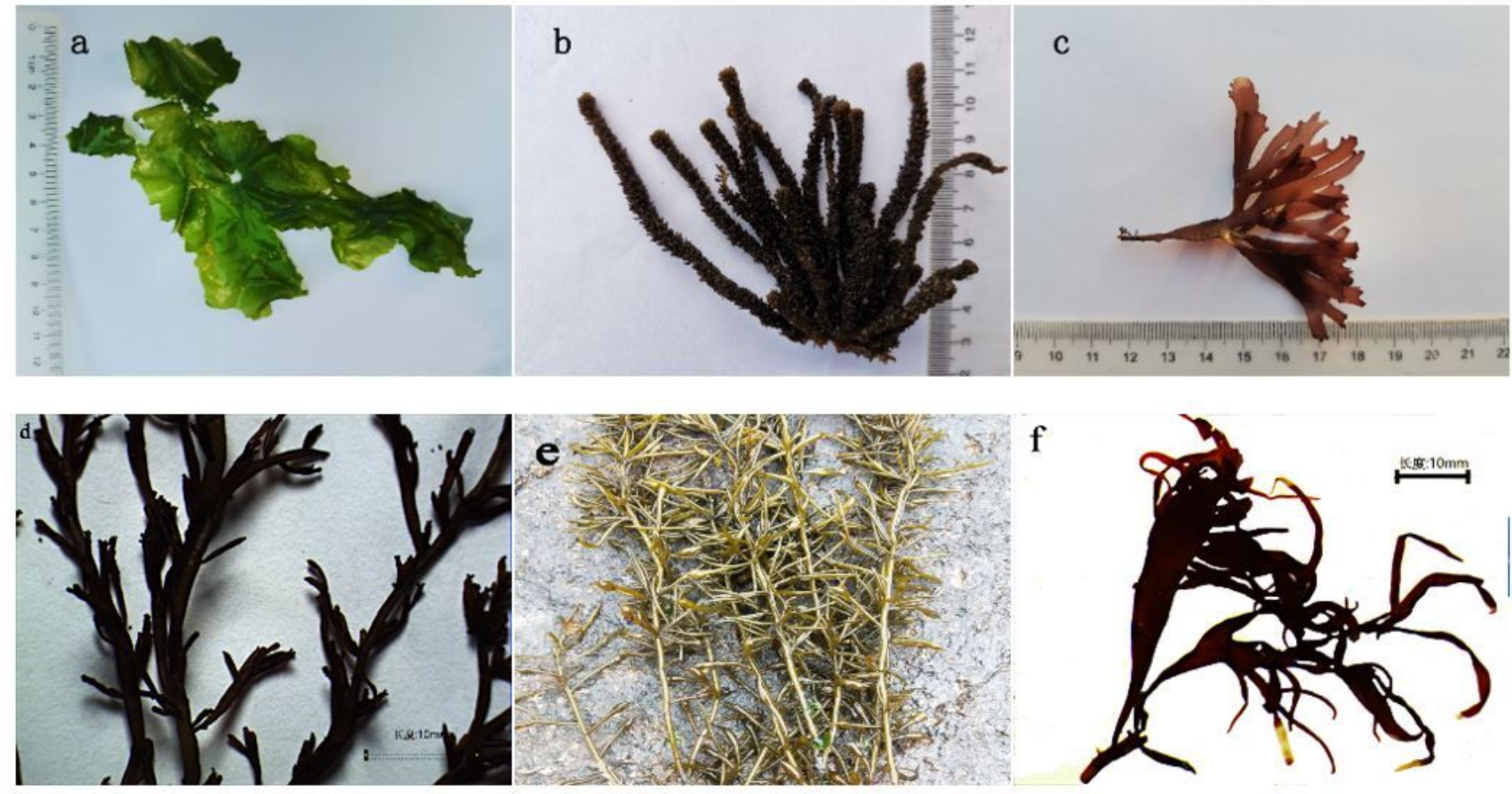
Figure 2

Dominant species in the intertidal zone of Gouqi Island. a) Ulva pertusa; b) Sargassum thunbergii; c) Chondrus ocellatus; d) Chondria crassiaulis; e) Hizikia fusifarme; f) Grateloupia filicina.
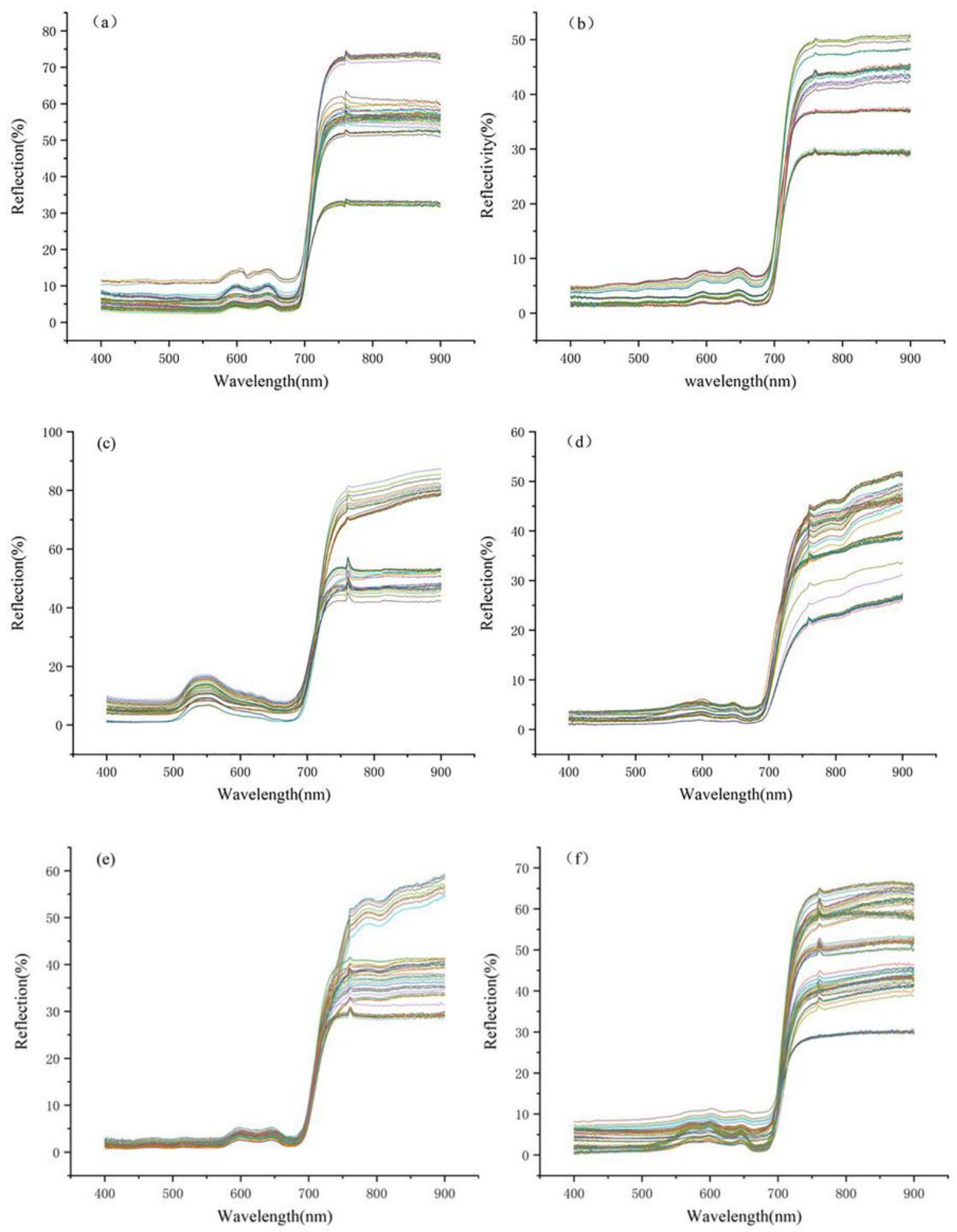

Figure 3 
Spectral curves of six species of seaweeds. a) Chondria crassiaulis; b) Chondrus ocellatus; c) Ulva pertusa; d) Sargassum thunbergii; e) Grateloupia filicina; f) Hizikia fusifarme.

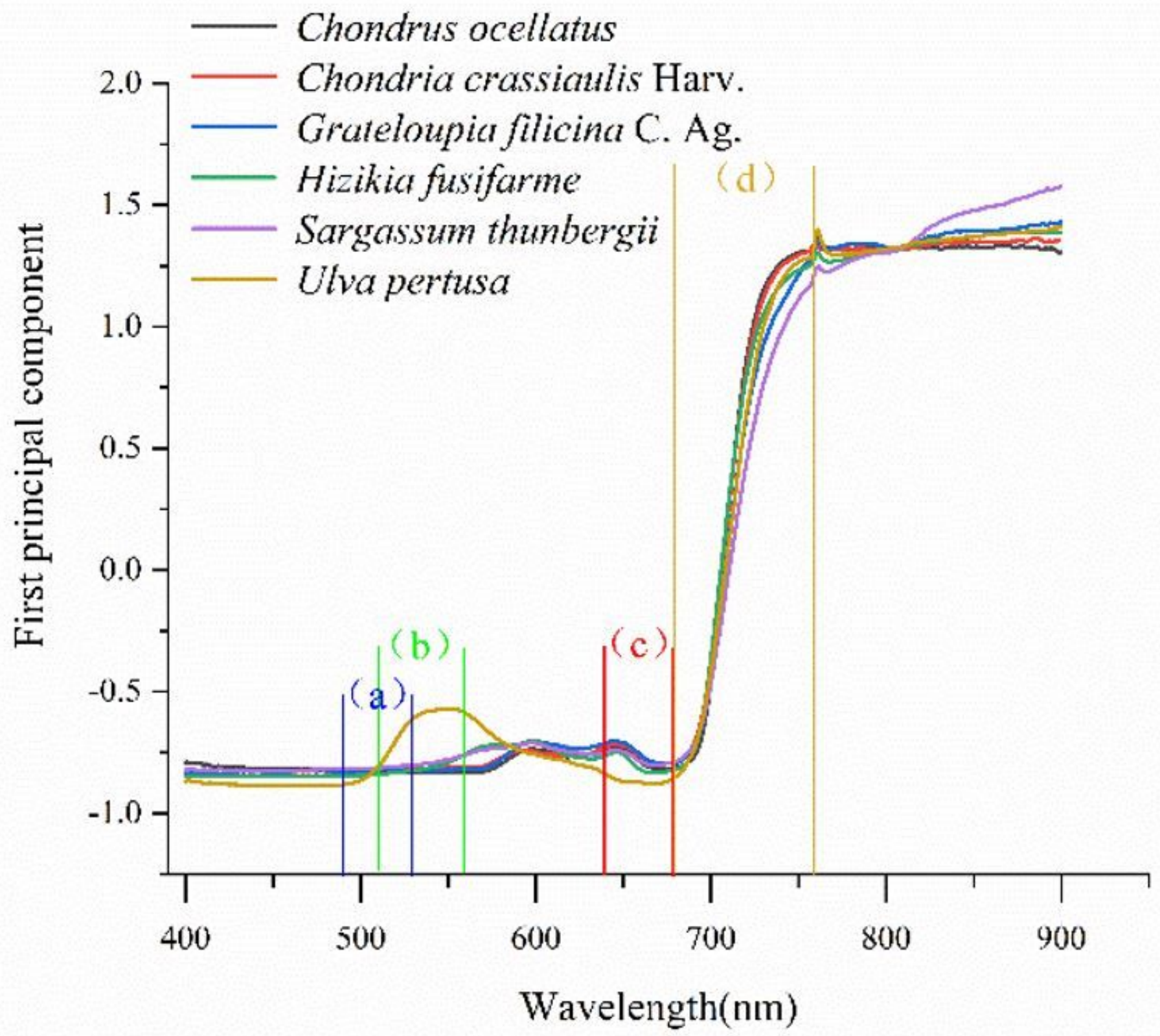

Figure 4

Spectral curves of the first principal component. 

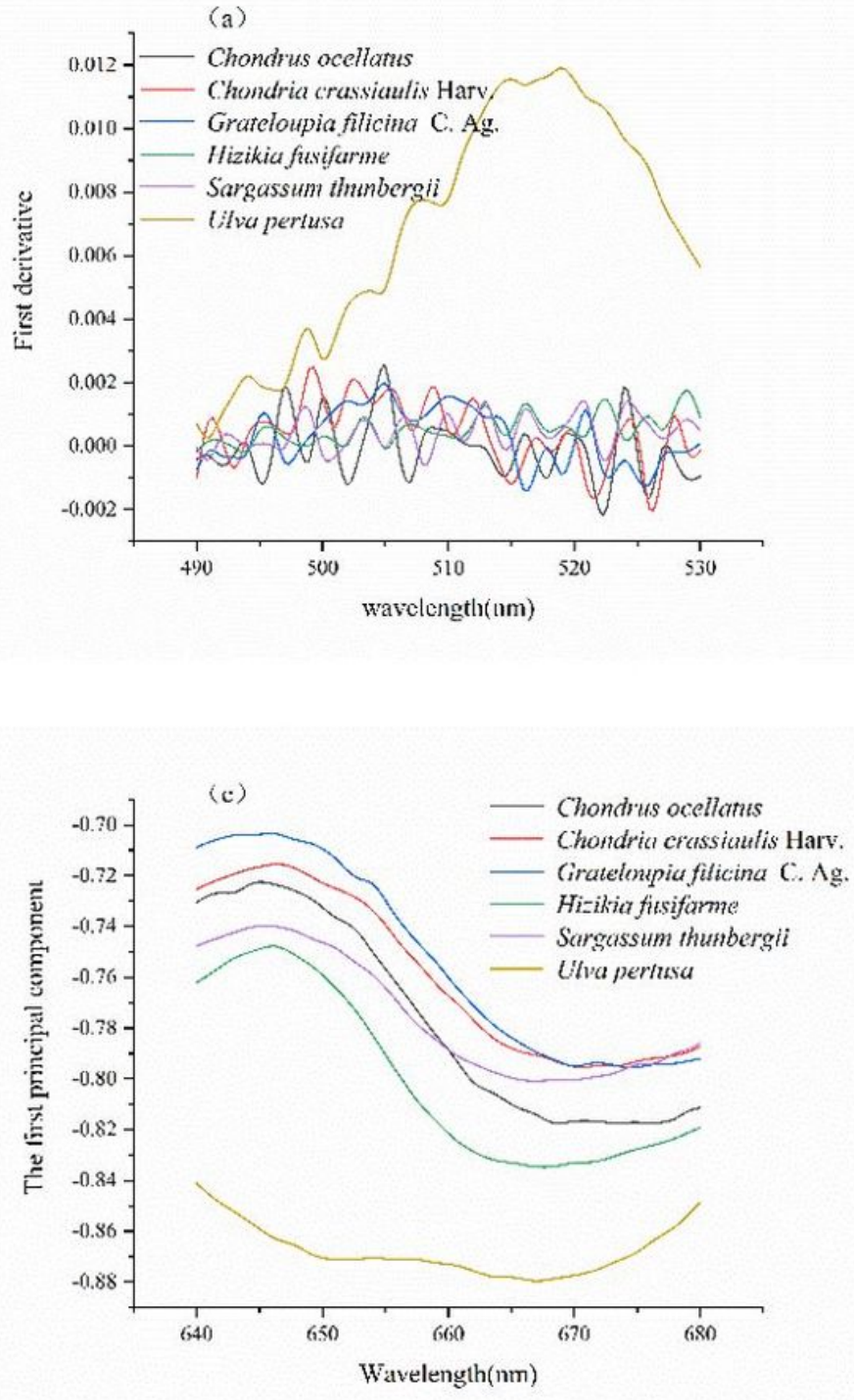
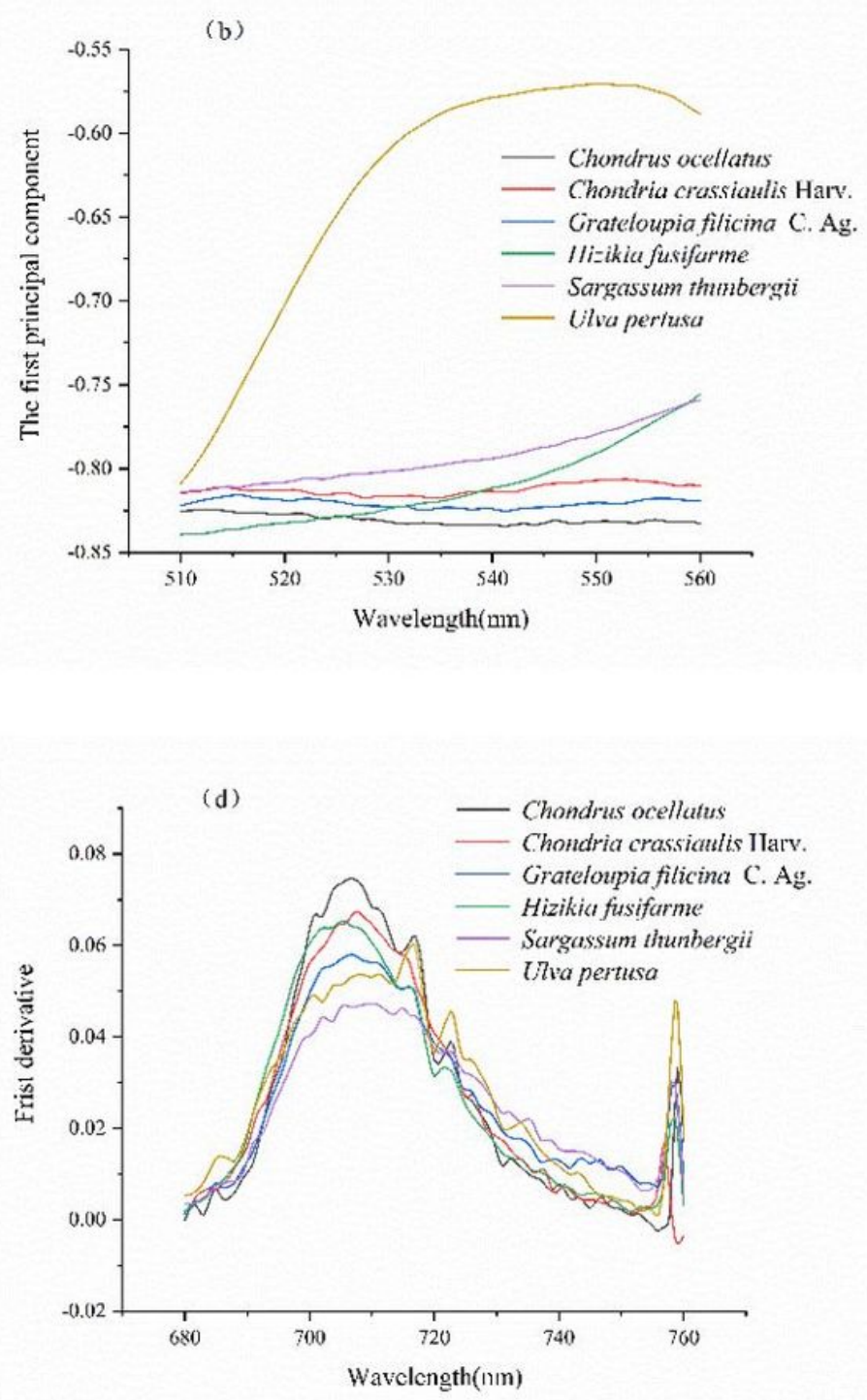

\section{Figure 5}

Spectrum enlarged view of green valley, red valley, blue edge and red edge locations. a) Enlarged image of the first-order differential spectrum at 490-530 nm (blue border area); b): Enlarged image of the spectrum at 510-560 $\mathrm{nm}$ (green peak area); c): Enlarged image of the spectrum at 640-680 nm (red valley area); d): Enlarged image of the first-order differential spectrum at 680-760 nm (red area). 


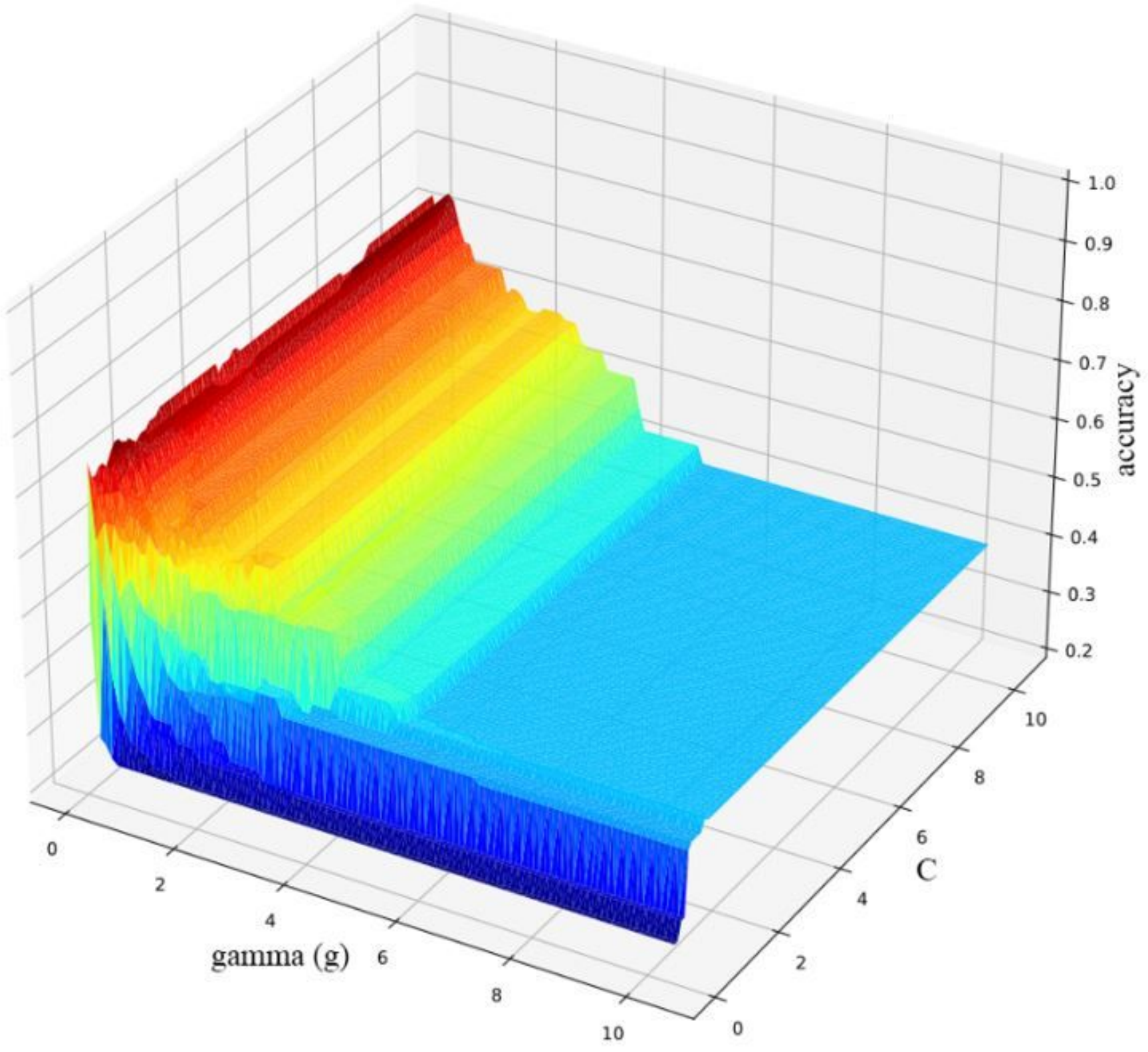

Figure 6

Parameter selection result (difference in seaweed species). 


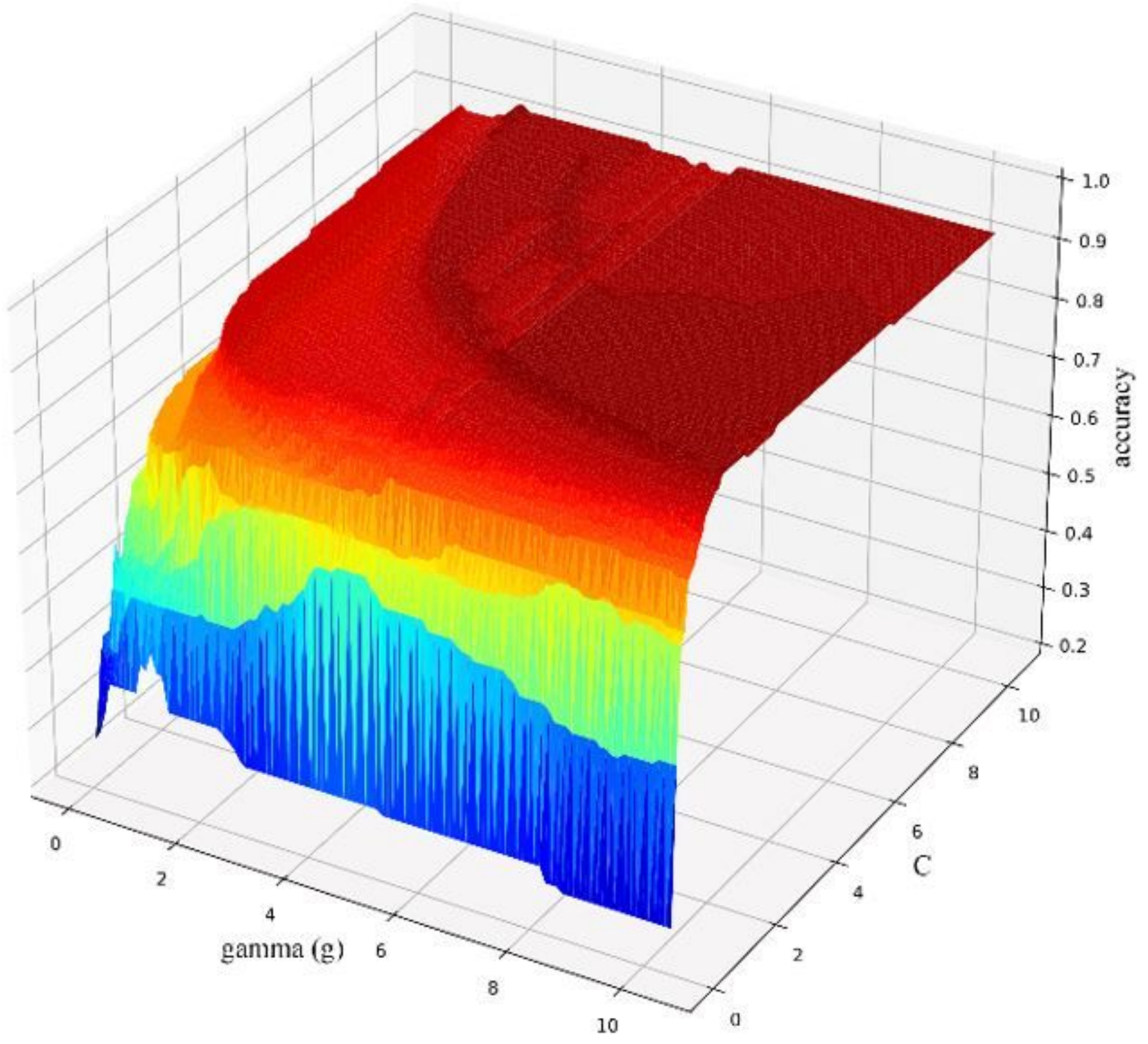

Figure 7

Parameter selection result (different phyla of seaweed). 


\section{Classification results}

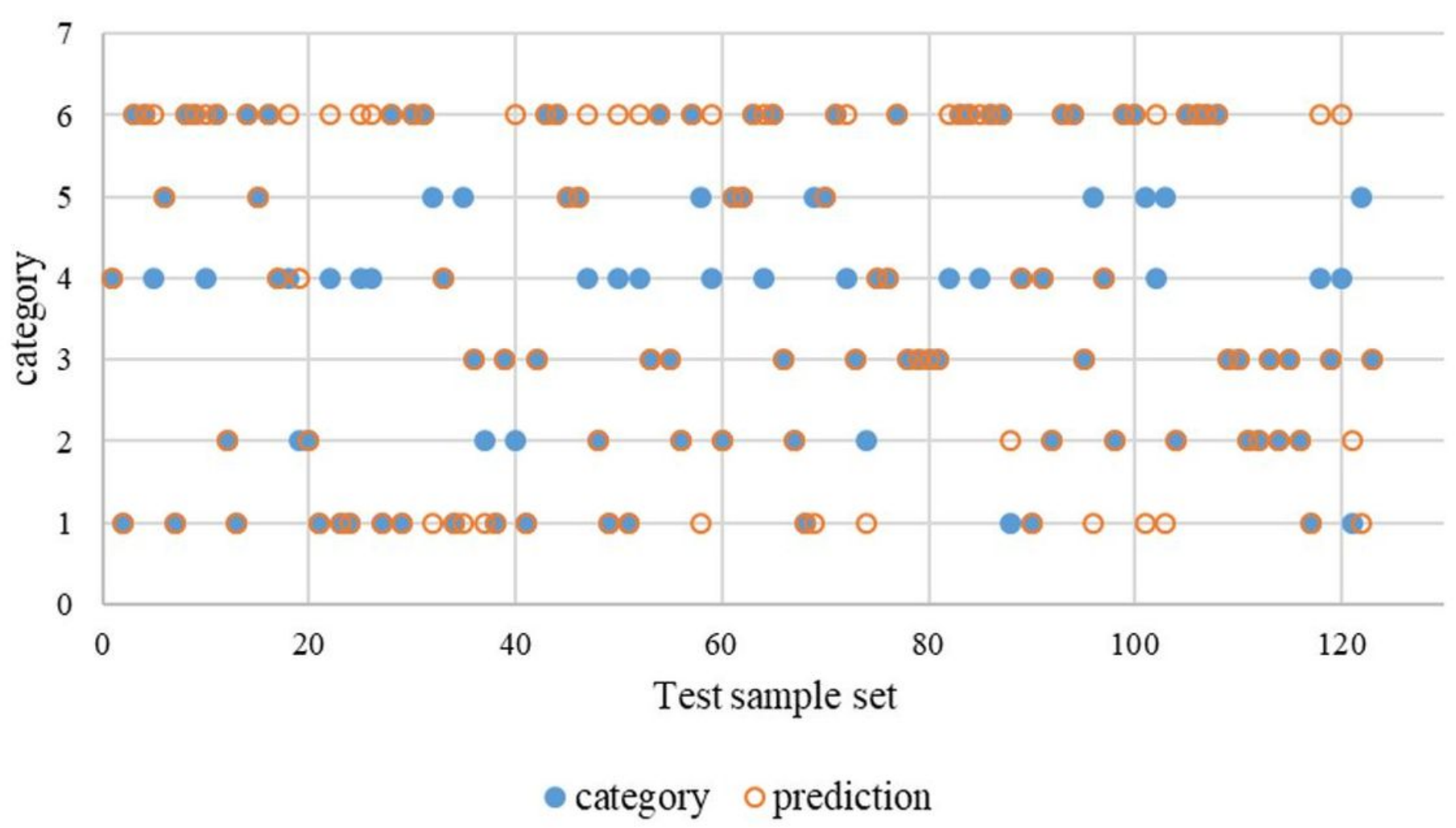

Figure 8

Classification results

\section{Supplementary Files}

This is a list of supplementary files associated with this preprint. Click to download.

- Supplementarymaterial.docx 